\title{
Toksikologicheskaya khimiya. Metabolizm i analiz toksikantov (Toxicological Chemistry: Toxicant Metabolism and Analysis), A textbook for higher schools, Kaletina, N.I., Ed.
}

DOI: $10.1134 / \mathrm{S} 1061934809020208$

This book consists of eleven chapters written by known researchers and teachers working at the Division of Toxicological Chemistry of the Pharmaceutical Department of the Sechenov Medical Academy.

Chapter 1 describes the system of governmental control, clinical toxicological control, and forensic medical examination in Russia. It presents legal documents regulating and specifying the actions of the services of chemicolegal examination and clinical toxicological analysis. The second chapter is devoted to the classification of toxic substances and types of their toxic action on a human body. It considers the general ideas of biological markers, hepatotoxicity, hematotoxicity, nehpthrotoxicity and dermatotoxicity, and the major detoxification methods. The third chapter covers some aspects of molecular toxicology and, primarily, the correlations between toxicology and genomics, gene polymorphism and metabolomics. The fourth chapter is devoted to toxicant metabolism and biotransformation and excretion from an organism.

The methodology of chemical toxicological analysis is considered in detail in chapter 5. It considers correlations between the analysis steps, toxicant concentration in the sample, sample preparation methods, and the interpretation of the results. The characteristic features of chemical toxicological analysis are described in the diagnosis of acute poisonings and drug determination. The system of laboratory validation and GLP principles are considered. The central place in the book is given to the sixth chapter, which describes the present-day methods of toxicant determination in biological systems in detail. The data on immunochemical and electrochemical methods for determining toxicants are presented. Various chromatographic and optical methods of toxicant analysis are considered in detail and classifications, terms, and definitions are presented, along with examples of particular procedures.

Chapter 7 is entirely devoted to the metabolism, narcotic action and procedures for determining basic narcotic, psychotropic and strong substances: opiates, cannabioids, phenylalkylamines, cocaine, hallucinogens, barbiturates, 1,4-benzodiazepine derivatives, neuroleptics, thymoleptics, energizers, and also other monitored strong substances.

Chapter 8 is devoted to action on the human body and methods for determining toxicants from various chemical groups, except for drugs. The determination of alcohols, aldehydes and ketones, hydrocarbons, halogenated hydrocarbons, poisonous gases (carbon monoxide, hydrogen sulphide, nitrogen oxides, hydrogen cyanide, pesticides, toxic metal ions, etc.) is described. Chapters 9 and 10 briefly describe methods for determining doping agents and ecotoxicants. The final, eleventh chapter is devoted to biological dangers and biological terrorism. At the end of the book, the list of recommended literature is presented (111 references) and the main abbreviations are listed.

In spite of the constant increase in the number of works in medicolegal and toxicological chemistry, we had no specialized books in this subject in Russian. The book under review is written in a vitalstyle, illustrated by numerous figures, graphs, and tables, which favors the better understanding of toxicological chemistry and interest in this subject. In addition, the textbook has an appendix Toksikologicheskaya khimiya. Situatsionnye zadachi i uprazhneniya (Toxicological chemistry: Situational problems and exercises; Kaletina, N.I., Ed., Moscow: GEOTAR-MEDIA, 2007, 352 pp). This collection has a UMO label. It includes problems and exercises used in the course of toxicological chemistry taught at the pharmaceutical department of the Moscow Medical Academy.

This text can be used as a reference book for experts in toxicological chemistry and a textbook for students of chemistry, ecology, and pharmacology specialized in toxicant analysis; it is also useful for all analysts who need to know the specific features of the determination of toxic and narcotic substances. 